\title{
Development of a new Sandvik 'little brother' dynamic rockbolt and the in situ dynamic evaluation of bolts
}

\author{
W Roach Sandvik Mining and Rock Technology, Australia \\ M Rataj Sandvik Mining and Rock Technology, Australia \\ B Darlington Sandvik Mining and Rock Technology, Australia
}

\begin{abstract}
Since the Australian mining industry's embracement of the D47 Mechanical Dynamic Extra (MDX) bolt, Sandvik has recently developed a smaller diameter version, the D39 MDX bolt. Sized for the Canadian, North American and European markets, the D39 MDX is similarly suitable for broken, very weak, strong and seismic rock conditions.

The major challenge during the design phase was determining how to fit the components into the smaller envelope while maintaining the desired dynamic capacity.

To test the performance of the D39 MDX bolt, the unique and well-proven Sandvik Dynamic Test Rig (DTR) was used. The DTR is a portable apparatus that simulates a seismic event by applying a dynamic impulse of up to $35 \mathrm{~kJ}$. The DTR records the load and displacement of the test bolt through a series of sensors. The test bolts can be installed in any mine site using standard installation procedures and bolting machinery.

Tests performed at mines showed the bolt is typically capable of absorbing an energy of $25 \mathrm{~kJ}$ (single impact) with displacements in the range of 120-143 mm.

The tests conducted have proven that the DTR can be used efficiently in bolt development, and it opens a considerable window of opportunity for future development and evaluation of dynamic rockbolts in actual conditions as opposed to in the laboratory environment.
\end{abstract}

The DTR also provides an opportunity to study the effects of mining progression on bolt performance as test bolts can be tested at any time interval after installation.

Keywords: rockbolt, dynamic, dynamic testing, seismic, in situ, ground support

\section{Introduction}

The demand for dynamic rockbolts is increasing. Several new rockbolt developments have been attempted with varying levels of success; their main setbacks have been either poor performance or arduous installation requirements, or a combination of both. Sandvik first developed the Mechanical Dynamic (MD) bolt, as shown in Figure 1, in 2009. The MD bolt is composed of a $47 \mathrm{~mm}$ diameter split tube, a solid rebar, a wedge assembly (a mechanical anchor consisting of fixed wedge(s) and a travelling wedge) and a stopper (a safety device used to restrain the rebar in the split tube in the event of rebar overload) to create a single-pass high-capacity rockbolt. Efficient and straightforward to install, the MD bolt is successfully used in many underground mines. The MD bolt has proven very effective for non-seismic dynamic conditions such as swelling ground; however, it has somewhat limited capacity for seismic applications. The MD bolt's typical energy absorption is $20 \mathrm{~kJ}$ with $250 \mathrm{~mm}$ displacement. 


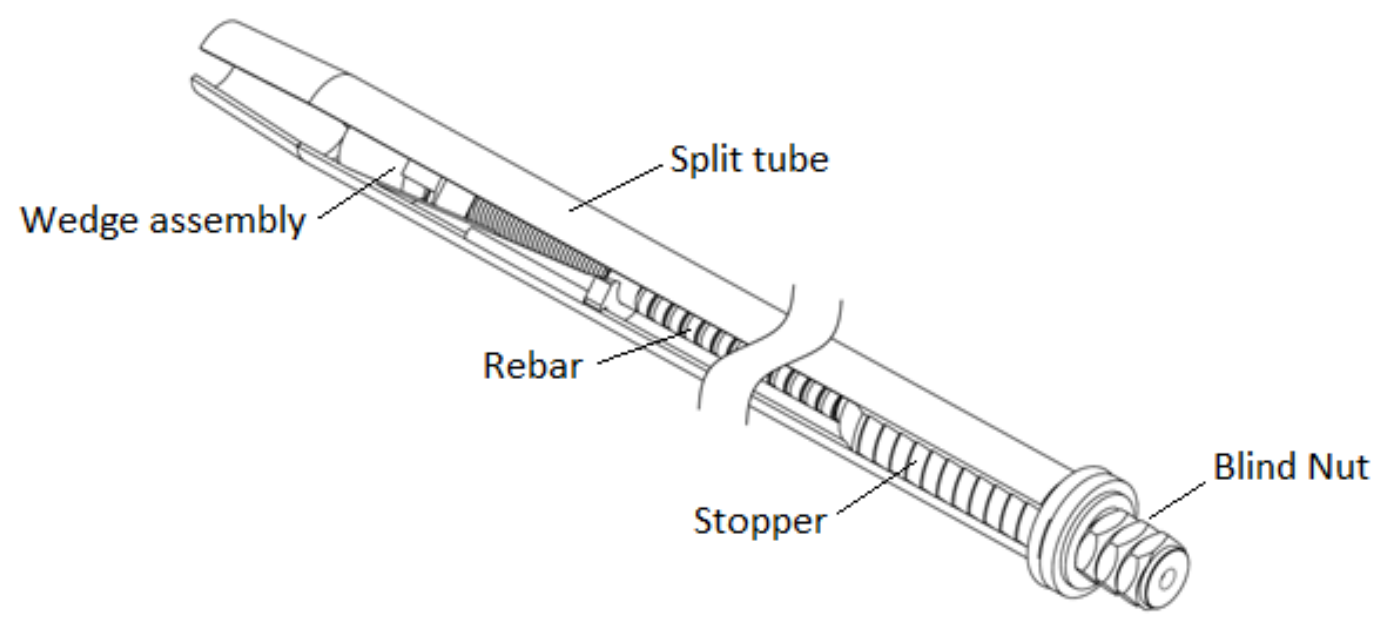

\section{Figure 1 The Sandvik MD bolt}

To improve on the dynamic (seismic) capacity of the MD bolt, the Mechanical Dynamic Extra (MDX) bolt was developed. Like the MD bolt, the MDX bolt is a single-pass bolt installation using conventional machinery and tools. The MDX bolt's evolution from the MD bolt involved two key design changes: the wedge assembly and the mechanism for load transfer, which allow the MDX bolt to provide a higher capacity of dynamic energy absorption. The MDX bolt's typical energy absorption is $25 \mathrm{~kJ}$ with $150 \mathrm{~mm}$ displacement. In addition, the MDX bolt consistently performs well in a greater range of ground conditions.

The first MDX bolt (i.e. the D47 MDX) bolt was developed in 2017 and features a $47 \mathrm{~mm}$ diameter split tube. The D47 MDX bolt, as shown in Figure 2, has been effectively introduced into several underground mines that required dynamic ground support systems.

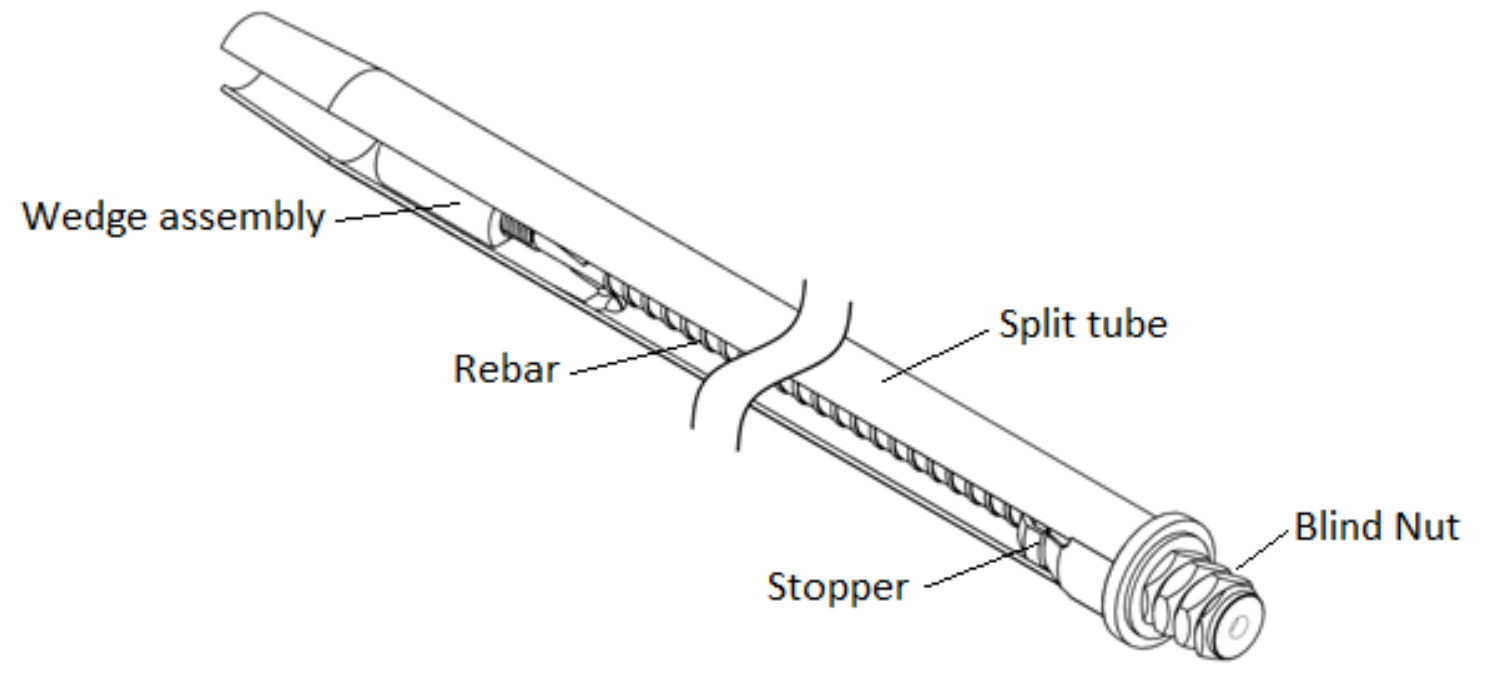

Figure 2 The Sandvik D47 MDX bolt

The wedge assembly of the D47 MDX bolt is designed to maximise expansion. The increase in expansion provides a two-fold benefit: the bolt is suitable for a greater range of ground conditions, and the wedge assembly assists with the absorption of higher levels of dynamic energy.

"Possibly the most important design change to the MDX bolt, is the load transfer mechanism. The MD bolt utilises both tube and re-bar components to absorb load, whereas the MDX bolt relies solely on the re-bar to absorb dynamic loads. This design alteration is the key to consistent responses when subjecting the MDX bolt to dynamic loading." (Darlington et al. 2018) 
This design alteration to the load transfer mechanism is also key for the D47 MDX bolt's relatively high $(25 \mathrm{~kJ})$ energy absorption and its suitability to virtually any rock condition.

After the success of the D47 MDX bolt in the Australian market, the development of the D39 MDX bolt began. The D39 MDX bolt is shown in Figure 3 and is based around a $39 \mathrm{~mm}$ diameter friction bolt tube. This smaller diameter bolt was developed for the bolting equipment typically used in Canada, North America and Europe. It may also be suitable for hand installation using an air leg.

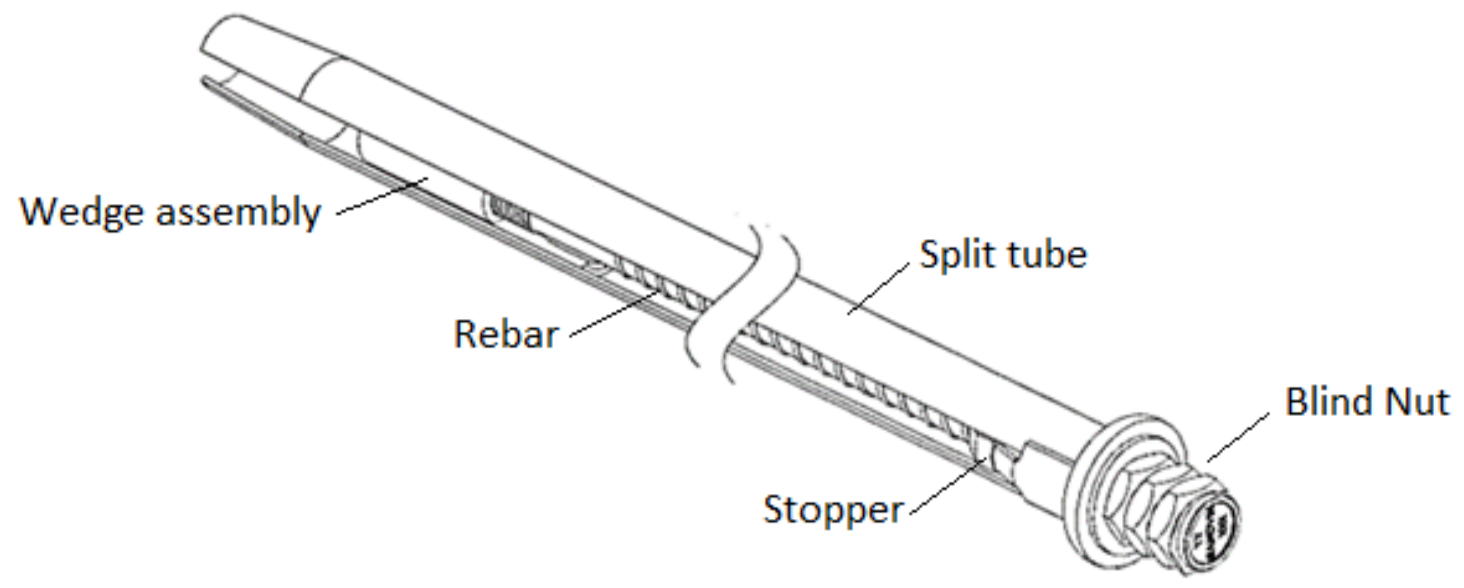

Figure 3 The Sandvik D39 MDX bolt

\section{Methodology}

\subsection{Bolt design}

The set requirements for the dynamic capacity of a rockbolt are that the rockbolt must absorb an energy of $25 \mathrm{~kJ}$ and displace not more than $300 \mathrm{~mm}$.

The design criteria for the D39 MDX bolt was based around the D47 MDX bolt comprising the same size rebar (i.e. $20 \mathrm{~mm}$ diameter), a smaller $39 \mathrm{~mm}$ diameter split tube and a proportionally sized wedge assembly and stopper. Having a successful 'big brother' allowed the initial concepts and prototypes to be expedited. The major design challenge was arranging the components into the confined envelope between the smaller tube and the rebar while optimising the desired expansion and dynamic capacity.

The wedge assembly configuration was designed first using 3D modelling to optimise the design for maximum expansion. Prototype manufacture then allowed verification of the system's strength via in-house laboratory testing. The desired result was achieved after one design iteration.

Similarly, the stopper was 3D modelled, and prototypes were injection moulded for initial in-house testing. On review of the test results, some design changes were made to improve the absorption characteristics of the stopper.

The next step was to prototype a complete bolt for in situ static testing and then, once proven successful, in situ dynamic testing.

\subsection{In situ evaluation of bolts}

In 2012, Sandvik identified the need for an in situ testing device and the associated benefits of testing in this manner. To fulfil this need, Sandvik designed and constructed the portable in situ Dynamic Test Rig (DTR). The DTR is capable of being transported to any mine site and testing any form of rockbolt in any type of rock. An initial prototype apparatus was used in association with Mikula Geotechnics and Rocktech for the introduction of the Sandvik MD bolt at the Mt Charlotte gold mine in 2013 (Carlton et al. 2013). The results from this testing further highlighted the need for a fully functional DTR. 
On completion, the Sandvik DTR was utilised from 2013 to verify the performance of the Sandvik MD bolt at five mine sites across Australia. During this test period, a number of design improvements to the DTR were implemented to further increase both the speed and ease of testing.

The Sandvik DTR uses the energy application technique by freefalling a mass onto a plate at the bottom of the drop bar. It can apply dynamic energies of up to $35 \mathrm{~kJ}$ in a single impact. The input energy is increased to compensate for the losses that occur in the test apparatus due to the elasticity of the load-bearing components. A typical test regime will apply a single dynamic impact to the test bolt; however, multiple impacts on one bolt are possible. The applied energy is easily modified by adjusting the drop mass or the drop height. The impact velocity is typically maintained between 5.2 and $5.7 \mathrm{~m} / \mathrm{s}$.

The Sandvik DTR, like any laboratory facility, is capable of both non-destructive and destructive dynamic testing. In both testing scenarios, the DTR captures the load applied to the bolt and the acceleration of the bolt. A piezoelectric load cell measures the load applied to the bolt, and an accelerometer provides the data, allowing the calculation of the bolt's displacement. Both sensors record at $25 \mathrm{kHz}$ and link directly to a control box. Due to the test environment, both signals can include some signal noise; this noise is attenuated using low-pass filters. The drop mass is released using a remotely operated control, with a maximum safe release distance of $50 \mathrm{~m}$.

The method used to connect the DTR to the rockbolt is important, as this contains the sensors and minimises the time required to test each rockbolt. The current embodiment, as shown in Figure 4, is in the form of a patented two-part claw assembly, which contains domed connections top and bottom. These domed connections allow for variations in bolt installation angle of up to $10^{\circ}$ from vertical. In this configuration, the DTR can apply not only axial loads but also a portion of shear and bending loads, which closer represents the loadings during a seismic event, which are not necessarily always in the axial direction of the bolt. A study testing the effect of the bolt installation angle on the dynamic performance of the bolt is planned for the future. The average test time is one bolt per hour.

Additional benefits of in situ testing include 'delayed' testing, where samples are tested sometime after installation. This test method will provide insight into the effects of mining progression, localised ground movement and exposure to groundwater on the dynamic performance of ground support elements.

During 2016 and 2017, Sandvik's DTR verified the design and performance of the Sandvik D47 MDX bolt at two mine sites in Australia.

In order to verify the design and determine the performance of the Sandvik D39 MDX bolt under dynamic loading conditions, in situ dynamic testing was conducted using Sandvik's DTR in 2018 at Kirkland Lake Gold's Fosterville gold mine, Australia (Mine A), and Craig mine, Levack, Canada (Mine B).

The loading sequence for the dynamic testing was divided into three input loading levels:

- Qualification energy (<25 kJ).

- Specification energy (25-27 kJ).

- High energy ( $\geq 27 \mathrm{~kJ})$.

The qualification energy level $(21-25 \mathrm{~kJ})$ was used primarily to gauge the performance of the bolts at a lower impact energy because these were the first D39 MDX bolts subjected to dynamic loading. The specification energy level $(25-27 \mathrm{~kJ})$ was used for a minimum of four samples. As the bolt responses suggested some additional capacity, the remaining samples were tested within the high energy level (27-28 kJ), which were used to identify the 'spare' capacity available in the D39 MDX bolt. 


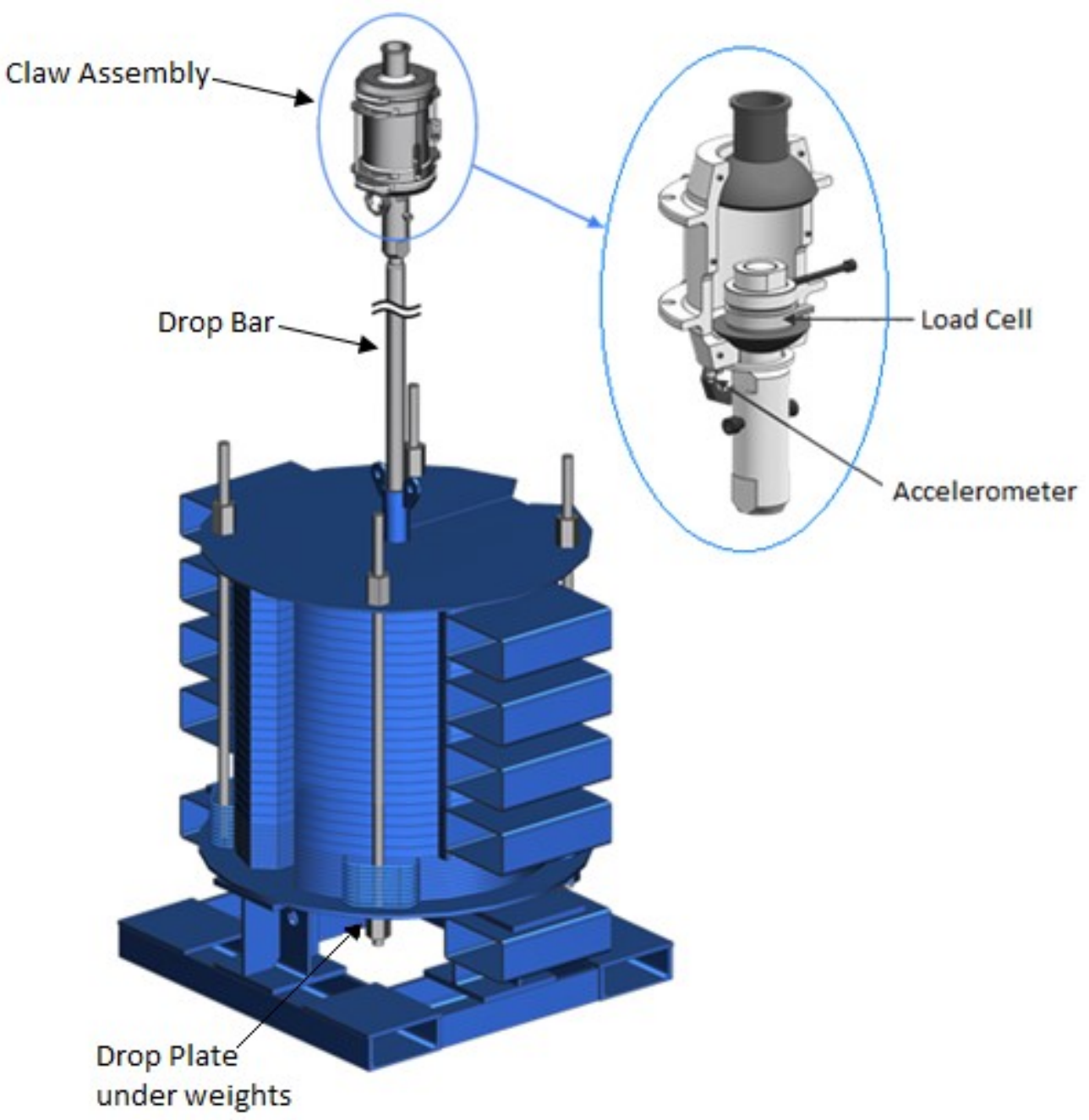

\section{Figure 4 Sandvik's Dynamic Test Rig}

\section{Data}

For Mine A, the general strata in the test area location was a competent blocky rock mass of interbedded sandstone with shale and some quartz inclusion with a typical ultimate compressive strength (UCS) of $50 \mathrm{MPa}$.

For Mine B, the general strata in the test area location was a competent blocky rock mass of norite with a typical UCS of $215 \mathrm{MPa}$.

The installation of the test bolts follows the standard installation procedure steps:

- Drill a hole to the required diameter and length.

- Hammer the bolt into the hole with no driver rotation and with water on.

- After the bolt is fully inserted, rotate the driver left-hand rotation without percussion until the drifter stalls $(350-400 \mathrm{Nm})$.

Each bolt was tested for installation quality, using a torque wrench to measure the pre-stress of the rebar, the data of which is outlined in Table 1 for Mine A and Table 2 for Mine B. 
Table 1 Data from the installation quality tests at Mine $\mathrm{A}$

\begin{tabular}{cccc}
\hline $\begin{array}{c}\text { Sample } \\
\text { ID }\end{array}$ & $\begin{array}{c}\text { Bolt length } \\
(\mathbf{m})\end{array}$ & $\begin{array}{c}\text { Static torque } \\
(\mathbf{N m})\end{array}$ & Comments \\
\hline 1 & 2.4 & 400 & - \\
2 & 2.4 & 400 & - \\
3 & 2.4 & 400 & - \\
4 & 2.4 & 450 & - \\
5 & 2.4 & 400 & - \\
6 & 2.4 & 350 & - \\
7 & 2.4 & 480 & - \\
8 & 2.4 & 390 & Tightened to $400 \mathrm{Nm}, 1 / 4$ turn \\
\hline 9 & 2.4 & 450 & \\
10 & 2.4 & 320 & \\
\hline
\end{tabular}

Table 2 Data from the installation quality tests at Mine B

\begin{tabular}{cccc}
$\begin{array}{c}\text { Sample } \\
\text { ID }\end{array}$ & $\begin{array}{c}\text { Bolt length } \\
(\mathbf{m})\end{array}$ & $\begin{array}{c}\text { Static torque } \\
(\mathbf{N m})\end{array}$ & Comments \\
\hline 1 & 2.4 & 450 & - \\
2 & 2.4 & - & No test \\
3 & 2.4 & 400 & - \\
4 & 2.4 & 400 & - \\
5 & 2.4 & 400 & - \\
6 & 2.4 & 400 & - \\
7 & 2.4 & 400 & - \\
8 & 2.4 & 400 & - \\
9 & 2.4 & 400 & - \\
10 & 2.4 & 400 & - \\
\hline
\end{tabular}

The data from the in situ dynamic tests conducted at Mine A and Mine B are outlined in Tables 3 and 4. It can be calculated from the data in these tables that impact velocities varied from 5.2 to $5.7 \mathrm{~m} / \mathrm{s}$ for input energies from 20.9 to $28.4 \mathrm{~kJ}$ respectively. The 'absorbed energy' value was obtained from integrating the measured load $(\mathrm{kN})$ by the calculated bolt displacement $(\mathrm{mm})$. Typically, the energy absorbed ranged from 90 to $98 \%$ of the input energy, reflecting the losses in the test apparatus.

The displacement of each bolt is calculated using the output from the accelerometer positioned in the claw assembly (Figure 4), where the acceleration signal is integrated twice to obtain the displacement relative to time. The position of the test bolt is also manually measured and photographed before and after the test relative to a fixed point to allow verification of the calculated displacement. The calculated displacement is used for analysis of the data because this is captured at the same frequency as the load applied to the bolt. 
Table 3 Data from in situ dynamic tests conducted at Mine A

\begin{tabular}{cccccccc}
\hline $\begin{array}{c}\text { Sample } \\
\text { ID }\end{array}$ & $\begin{array}{c}\text { Loading } \\
\text { mass } \\
(\mathbf{k g})\end{array}$ & $\begin{array}{c}\text { Drop } \\
\text { height } \\
(\mathbf{m})\end{array}$ & $\begin{array}{c}\text { Input } \\
\text { energy } \\
(\mathbf{k J})\end{array}$ & $\begin{array}{c}\text { Absorbed } \\
\text { energy } \\
(\mathbf{k J})\end{array}$ & $\begin{array}{c}\text { Peak input } \\
\text { load } \\
\mathbf{( k N )}\end{array}$ & $\begin{array}{c}\text { Calculated bolt } \\
\text { displacement } \\
(\mathbf{m m})\end{array}$ & $\begin{array}{c}\text { Measured bolt } \\
\text { displacement } \\
(\mathbf{m m})\end{array}$ \\
\hline 1 & 1,547 & 1.38 & 20.9 & 18.7 & 268.7 & 80 & 76 \\
2 & 1,547 & 1.64 & 24.8 & 22.2 & 289.6 & 131 & 110 \\
3 & 1,832 & 1.44 & 25.8 & 24.2 & 282.0 & 111 & 105 \\
4 & 1,832 & 1.44 & 25.8 & 24.8 & 305.8 & 124 & 112 \\
5 & 1,832 & 1.44 & 25.8 & 23.2 & 319.6 & $300+$ & $300+$ \\
6 & 1,832 & 1.44 & 25.8 & 24.8 & 289.9 & 143 & 115 \\
7 & - & - & - & - & - & - & - \\
8 & 1,832 & 1.44 & 25.8 & 21.1 & 282.7 & 116 & 105 \\
9 & 1,832 & 1.50 & 27.0 & 4.6 & 249.7 & $300+$ & $300+$ \\
10 & 1,832 & 1.50 & 27.0 & 25.6 & 263.5 & 133 & 105 \\
\hline
\end{tabular}

Table 4 Data from in situ dynamic tests conducted at Mine B

\begin{tabular}{cccccccc}
\hline $\begin{array}{c}\text { Sample } \\
\text { ID }\end{array}$ & $\begin{array}{c}\text { Loading } \\
\text { mass } \\
(\mathbf{k g})\end{array}$ & $\begin{array}{c}\text { Drop } \\
\text { height } \\
(\mathbf{m})\end{array}$ & $\begin{array}{c}\text { Input } \\
\text { energy } \\
(\mathbf{k J})\end{array}$ & $\begin{array}{c}\text { Absorbed } \\
\text { energy } \\
(\mathbf{k J})\end{array}$ & $\begin{array}{c}\text { Peak input } \\
\text { load } \\
(\mathbf{k N})\end{array}$ & $\begin{array}{c}\text { Calculated bolt } \\
\text { displacement } \\
(\mathbf{m m})\end{array}$ & $\begin{array}{c}\text { Measured bolt } \\
\text { displacement } \\
(\mathbf{m m})\end{array}$ \\
\hline 11 & 1,547 & 1.40 & 21.2 & 18.5 & 266 & 93 & 75 \\
12 & - & - & - & - & - & - & - \\
13 & 1,547 & 1.63 & 24.7 & 24.3 & 353 & 106 & 85 \\
14 & 1,832 & 1.45 & 26.1 & 25.3 & 281 & 120 & 115 \\
15 & 1,832 & 1.45 & 26.1 & 14.8 & 194 & $300+$ & $300+$ \\
16 & 1,832 & 1.45 & 26.1 & 23.6 & 296 & 110 & 108 \\
17 & 1,832 & 1.45 & 26.1 & 25.7 & 276 & 125 & 110 \\
18 & 1,832 & 1.51 & 27.1 & 24.9 & 361 & 128 & 123 \\
19 & 1,832 & 1.51 & 27.1 & 24.9 & 358 & 126 & 120 \\
20 & 1,832 & 1.58 & 28.4 & 26.7 & 350 & 134 & 123 \\
\hline
\end{tabular}

\section{$4 \quad$ Results}

For each of the three loading levels, as described previously, there was a range of displacements. For the qualification, specification and high loading levels, the displacements ranged from 80 to $131 \mathrm{~mm}, 110$ to $143 \mathrm{~mm}$ and 126 to $134 \mathrm{~mm}$ respectively (bolts that arrested the applied dynamic load). A Pearson correlation coefficient of 0.8 , indicating a strong positive linear correlation between the absorbed load and the calculated bolt displacement, as illustrated in Figure 5, provides a high confidence in the expected performance of the bolt. 


\section{Energy vs Displacement}

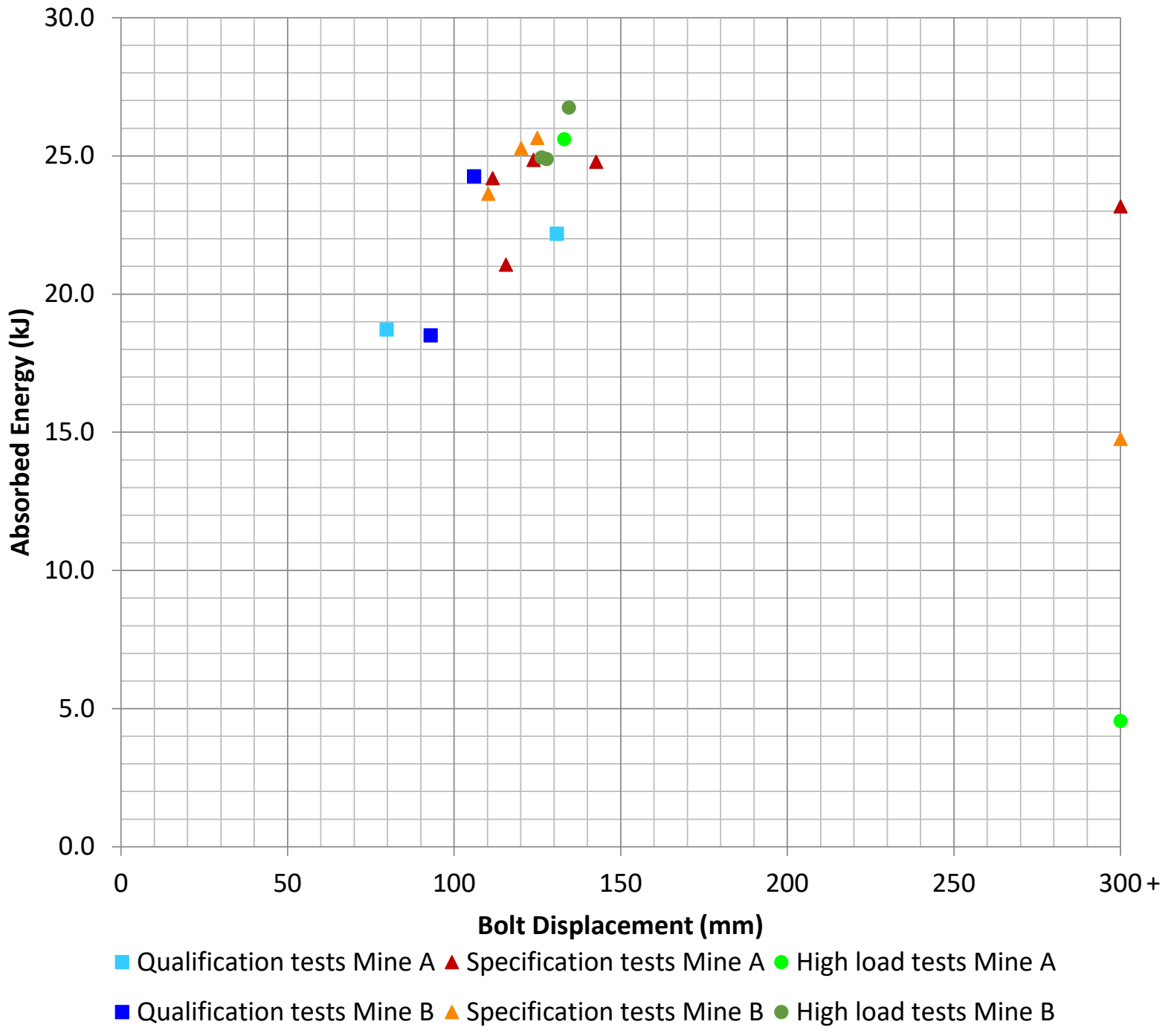

Figure 5 Absorbed energy plotted against bolt displacement

From Figure 5, it can be concluded that the D39 MDX bolts absorbed the nominal $25 \mathrm{~kJ}$ energy with a bolt displacement nominal range of 120 to $143 \mathrm{~mm}$.

Sample 5 was measured to have an installation angle of $12^{\circ}$ but was tested due to the limited number of samples. The bolt failed to arrest the applied dynamic load of $25.8 \mathrm{~kJ}$, absorbing $23.2 \mathrm{~kJ}$ prior to failure. The installation angle was believed to be the cause of this ductile failure.

Sample 7 was not tested due to poor installation angle: $>10^{\circ}$.

Sample 9 failed to arrest the applied dynamic load of $27 \mathrm{~kJ}$, absorbing only $4.6 \mathrm{~kJ}$ prior to failure, pulling the rebar out of the tube. The rebar and travelling wedge ( $T$-Wedge) were retrieved, and upon inspection, it was discovered that the failure mechanism was overloading the wedge system, resulting in the rebar and TWedge pulling past the welded wedges. Due to the lack of deformation shown on the T-Wedge, it was concluded that the cause was an extremely soft area of ground. 
Sample 12 was not tested due to restricted access to the head of the bolt.

Sample 15 failed to arrest the applied dynamic load of $26.1 \mathrm{~kJ}$ and pulled the rebar out of the tube. The failure mechanism was unknown because the rebar was not retrieved from the tube. As this bolt absorbed only $14.8 \mathrm{~kJ}$ energy, it was deduced that the failure mechanism was wedge overloading due to soft ground; see Figures 6 for fines that were found on top and inside the claws.

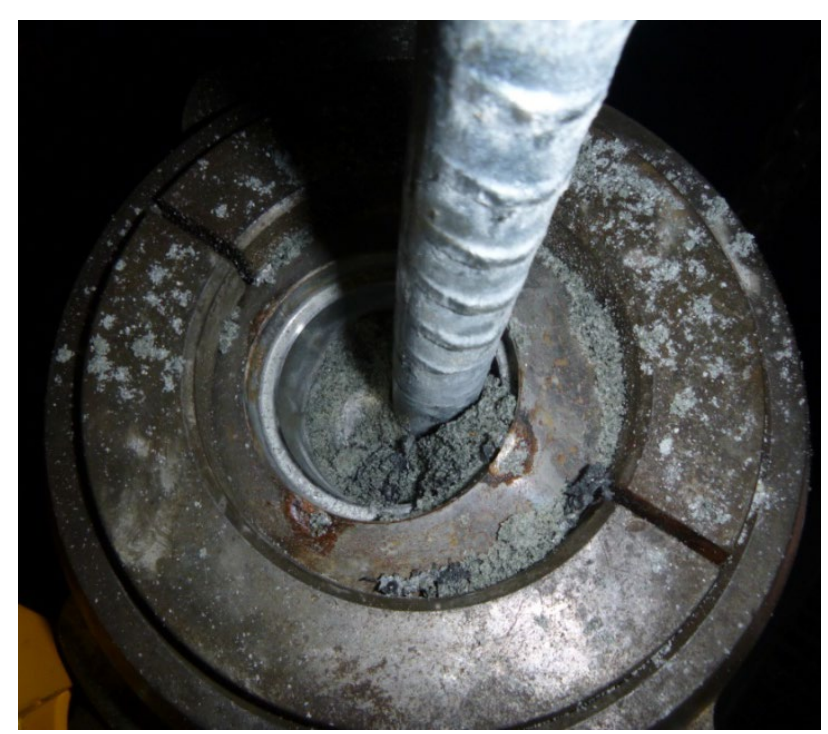

Figure 6 Fines on top of claws

Figure 7 shows a typical load versus displacement characteristic for a D39 MDX bolt. The response of the D39 MDX bolts to the dynamic loads was very consistent, which included a high peak load followed by a high sustained load.

\section{Load vs Displacement}

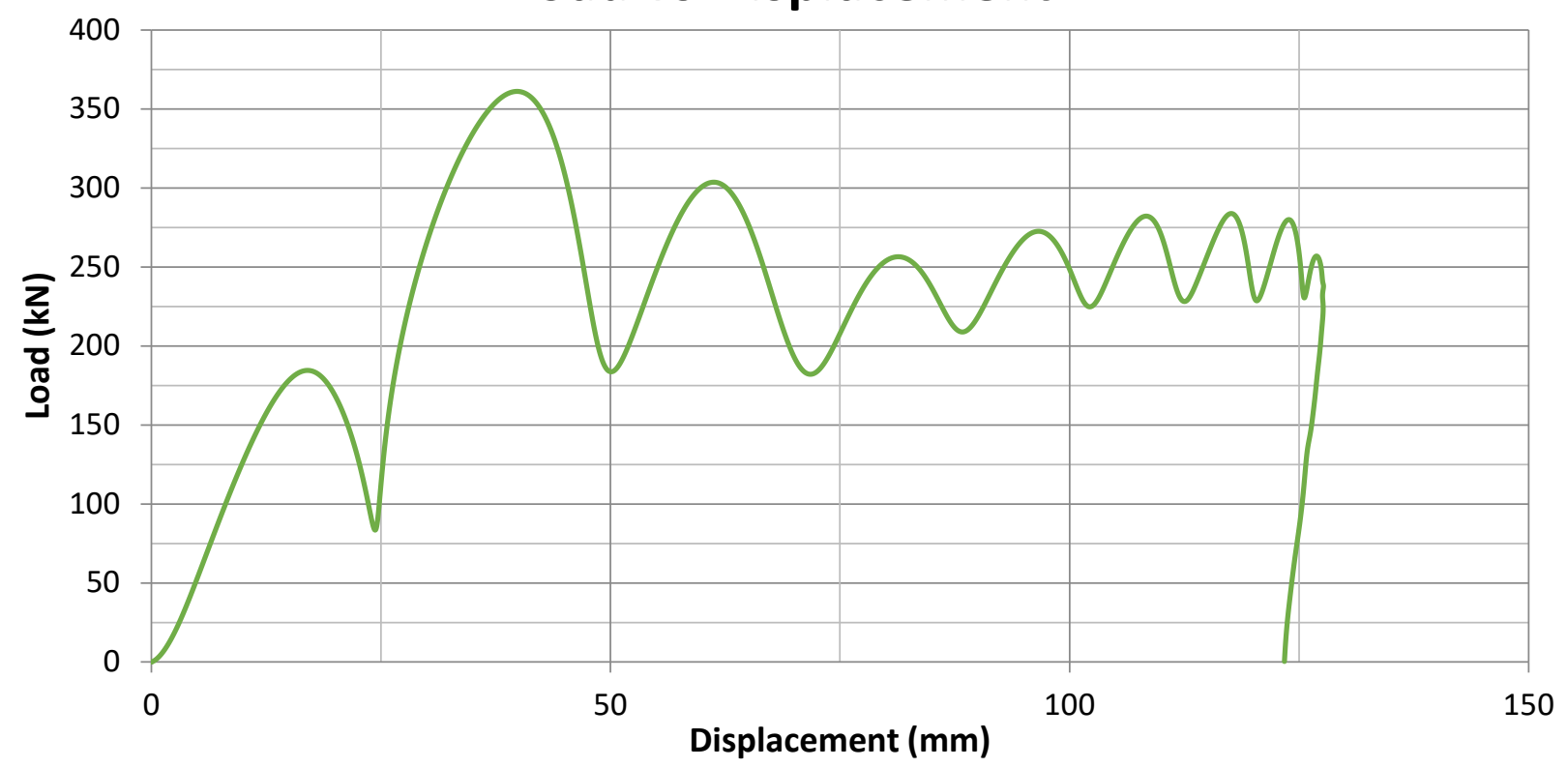

Figure 7 Sample 18 displacement response to loading

As shown in Figure 7, there are three distinct responses to the applied load. The initial peak of approximately $185 \mathrm{kN}$ is the load required to 'set' the wedge system, which is followed by the high peak load of approximately $360 \mathrm{kN}$ and then the third 'yielding' response of approximately 200 to $300 \mathrm{kN}$, where 
the energy is absorbed and the majority of the displacement occurs. These responses were typical of all bolts that arrested the applied load.

As shown in Figure 8, the initial 'wedge set' load ranged from 175 to $190 \mathrm{kN}$, and the peak load ranged between 235 to $360 \mathrm{kN}$.

\section{Load vs Displacement}

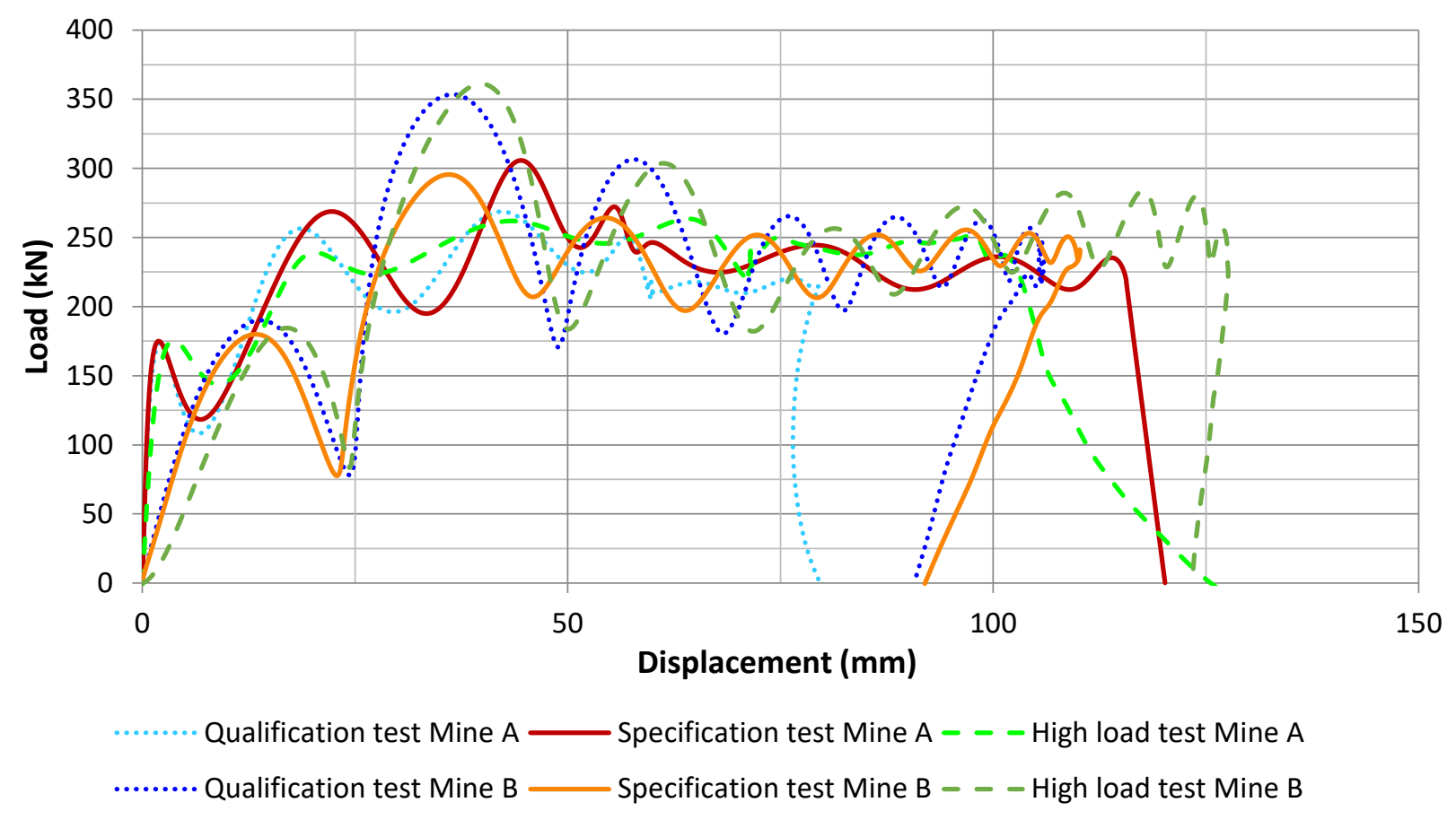

Figure 8 Summary of displacement response to applied loads

The primary mode of displacement experienced by the D39 MDX bolt was through elongation of the rebar component.

The recording of all installation angles will be implemented on future testing to initiate the study of the influence of bolt installation angle on the dynamic performance of rockbolts.

To identify between the three Sandvik bolts, the MD, D47 MDX and D39 MDX, a bolt ID system has been developed. This system integrates a colour-coded tab into the existing blind nut and has the bolt type and length printed on it to allow easy identification before and after installation.

\section{Conclusion}

The dynamic testing of Sandvik's D39 MDX bolts was successfully performed using the Sandvik in situ DTR, which simulates seismic loading.

The apparatus provided the high-resolution data required to accurately monitor the performance of the D39 MDX bolt under dynamic loading and site-specific rock conditions. With quick test times, an average of one bolt tested perhour, the in situ DTR can be used as a suitable test method to determine the performance of rockbolts in site-specific conditions.

While the testing in principle is planned to be non-destructive, it may also be accomplished in a destructive manner, as the bolt absorption level can be determined even if the bolt is overloaded (e.g. Samples 5, 9 and 15). 
The dynamic performance of the D39 MDX bolt has been proven. The requirement set for the D39 MDX bolt was to absorb an energy of $25 \mathrm{~kJ}$ and displace less than $300 \mathrm{~mm}$. From the results obtained, the D39 MDX bolt not only meets the requirement of the energy absorption but it does so with displacements of only 120 to $143 \mathrm{~mm}$, well below the specified $300 \mathrm{~mm}$.

\section{Acknowledgement}

During the process of designing and testing of the D39 MDX bolt, the work was the joint effort of the authors along with Peter Young and the employees of Kirkland Lake Gold's Fosterville gold mine, Australia, and Craig mine, Levack, Canada.

\section{References}

Darlington, B, Rataj, M, Balog, G \& Barnett, B 2018, 'Development of the MDX Bolt and in situ dynamic testing at Telfer Gold Mine', in C Li, X Li, \& Z Zhang (eds), Proceedings of the 3rd International Conference on Rock Dynamics and Applications (RocDyn-3) 2018, CRC Press, Leiden, pp. 403-408.

Carlton, R, Mikula, P \& Darlington, B 2013, 'In situ dynamic drop testing of the MD bolt at Mt Charlotte Gold Mine', in Y Potvin \& B Brady (eds), Proceedings of the Seventh International Symposium on Ground Support in Mining and Underground Construction, Australian Centre for Geomechanics, Perth. pp. 207-219. 
Development of a new Sandvik 'little brother' dynamic rockbolt

W Roach et al. and the in situ dynamic evaluation 'of bolts 